\title{
BMJ Open Impact of family physicians on cervical cancer screening: cross-sectional questionnaire-based survey in a region of southern Poland
}

\author{
Katarzyna Nessler, ${ }^{\odot}$ Sze Kay Florence Chan, Francis Ball, Monika Storman, ${ }^{\odot}$ \\ Michal Chwalek, Anna Krztoń-Królewiecka, Elżbieta Kryj-Radziszewska, \\ Adam Windak
}

To cite: Nessler K, Chan SKF, Ball F, et al. Impact of family physicians on cervical cancer screening: crosssectional questionnairebased survey in a region of southern Poland. BMJ Open 2019;9:e031317. doi:10.1136/ bmjopen-2019-031317

- Prepublication history for this paper is available online. To view these files, please visit the journal online (http://dx.doi org/10.1136/bmjopen-2019031317).

Received 02 May 2019 Revised 30 July 2019 Accepted 08 August 2019
D) Check for updates

(c) Author(s) (or their employer(s)) 2019. Re-use permitted under CC BY-NC. No commercial re-use. See rights and permissions. Published by BMJ.

Department of Family Medicine, Jagiellonian University Medical College, Kraków, Poland

Correspondence to Dr Katarzyna Nessler; katarzynanessler@gmail.com

\section{ABSTRACT}

Background Despite worldwide efforts in encouraging routine pap smears for early detection of cervical cancer, Poland's screening rate lags behind the rest of the European Union at $20.2 \%$. Family physicians (FPs) in Poland rarely perform pap smears, and little is known about the experiences and attitudes of Polish patients regarding pap smear screening in a primary healthcare (PHC) setting.

Methods A cross-sectional questionnaire-based survey was performed. Questionnaires were distributed among 43 FPs and 418 of their patients in one Polish region. The data from patients were associated with the doctors' characteristics. Descriptive statistics, the $\chi^{2}$ test and the Mann-Whitney U test were used for analysis.

Results Nearly two-thirds of patients (66\%) declared willingness to undergo free pap smear screening by their FPs, with the most common reason being time saved. Among those objecting to receive pap smears from their FPs, immediate specialist care provided by gynaecologists in case of adverse results was the main concern. The factors that positively influenced the patients' decision to undergo cervical cancer screening in PHC were: (1) living in a city with more than 100000 inhabitants, (2) being single, (3) having a female FP or (4) a physician with specialty training in family medicine.

Conclusion There is high level of acceptance for pap smears performed in PHC offices among patients in Poland. They are more likely to comply with the screening due to easy access. Establishing a solid physician-patient relationship is also crucial in encouraging screening.

\section{INTRODUCTION}

The WHO estimates that about 266000 women die of cervical cancer annually, making this one of the leading causes of cancer death in the world. Despite the high mortality rate, cervical cancer is a largely preventable disease. Human papillomavirus (HPV) is one of the most common sexually transmitted infections worldwide, and is noted as a necessary cause of cervical cancer development. ${ }^{12}$ In particular, high risk HPV
Strengths and limitations of this study

- Identification of the individual factors which may influence patients' behaviours when they are considering undergoing cytological testing at primary healthcare (PHC) office.

- Joining the patients' answers with the characteristics of their physicians.

- Study conducted in randomly selected PHC offices (minimal sample size reached in both the physician and patient groups).

- The percentage of women who would be willing to receive pap smears at their general practitioner office is high, which is valuable information from a cost-allocation perspective.

- Results are not fully representative of the whole Polish population (the survey only being conducted in one region).

subtypes 16 and 18 are commonly found to be present in cervical tumours. ${ }^{3-6}$

It is estimated that approximately $70 \%$ of cases of cervical cancer around the globe are associated with HPV types 16 and $18 .^{7}$ Active immunisation against these subtypes has shown to decrease the prevalence of $\mathrm{HPV}^{8}$ and the incidence of cervical malignancies. ${ }^{9}$ In addition to immunisation, routine Papanicolau testing (pap smear) is an effective screening tool that allows for early detection of cervical cancer. Studies have shown that cytological screening decreases the incidence ${ }^{10-12}$ and mortality rate of cervical cancer. $^{11-15}$

According to statistics collected in 2012 by Institut Catala d'Oncologia HPV Centre, over 1800 deaths occur every year as a result of cervical cancer in Poland, making it the second leading cause of cancer death in women. There is a national screening programme done by National Health Service 
Fund's which relies on sending invitations by post to encourage patients to perform regular pap smears. Despite that, the pap smear screening rate in Poland is a shockingly low $20.2 \%$, as compared with a $70 \%-80 \%$ screening rate in other European Union (EU) countries. ${ }^{16}$ In an effort to increase screening rates, pap smears are generally performed by primary healthcare (PHC) physicians in many countries all over the world such as Canada, Germany, Spain and Portugal, which greatly differs from Poland where pap smears are performed almost exclusively by gynaecologists. ${ }^{17} 18$

In addition, Poland is one of the few countries in the EU that does not currently have an HPV vaccination programme for target populations. ${ }^{16}$ In order to develop strategies that can efficiently accomplish cervical cancer prevention, it is essential to obtain a thorough understanding of the determinants contributing to the low screening rate in Poland. Implementing pap smears in PHC offices may be one of the solutions to increase the effectiveness of cervical cancer screening in Poland.

Our study aims to answer the following questions:

1. What is the PHC patient's experience with pap smear testing?

2. What is the level of the PHC patient's willingness to undergo screening at PHC offices?

3. Are there any associations between the professional characteristics of PHC physicians and their patients which could influence the readiness for cytological screening in a PHC setting?

\section{MATERIAL AND METHODS \\ Study design}

A cross-sectional questionnaire-based study was conducted from January to December 2017 in Malopolska region (Krakow and surrounding small towns and villages). The data were collected by medical students and physicians, who had all received appropriate training and instructions regarding the study protocol. All patients were surveyed after their visit to their family physician (FP), while all physicians completed their surveys at the end of the consultation session.

\section{Sampling}

The sample size was calculated using OpenEpi software. The sample size formula $n=[(\operatorname{DEFF} \times \mathrm{Np}(1 \mathrm{p})] /[(\mathrm{d} 2 /$ $\mathrm{Z} 21-\alpha / 2 \times(\mathrm{N}-1)+\mathrm{p} \times(1 \mathrm{p})]$ was used to calculate the number of patients and physicians needed for this study. For the patient sample (population size $n=1000000$ female inhabitants of Malopolska region aged 18-55, anticipated \% frequency of patients willing to undergo pap smear in a FP office population based on pilot study results $\mathrm{p}=36 \%$, absolute error or precision $\mathrm{d}=5 \%$, design effect $(\mathrm{DEFF})=1.0$, significance level $\alpha=5 \%$, $\mathrm{Z1}-\alpha / 2=1.96$ ), the minimum patient sample size (n) was estimated to be 354 . The minimum physician sample size was calculated to be $41(\mathrm{n}=702$ primary care practices registered in Malopolska region, $\mathrm{p}=87 \%, \mathrm{~d}=10 \%$,
$\mathrm{DEFF}=1.0, \alpha=5 \%, \mathrm{Z1}-\alpha / 2=1.96)$. As in survey research, physicians are recognised as a professional group from which it is difficult to obtain high responses, therefore, a sample size of 200 physicians was chosen. To avoid bias related to practices selection random sampling by means of random-number table was used. To draw the sample, we used a local register of PHC physicians provided by the National Health Service Fund.

\section{Patient and public involvement}

The purpose of the study was thoroughly explained to all participants. The study was conducted according to Guideline for Good Clinical Practice rules. The authors enforced the highest ethical standards for this study. The authors made sure that high standards were implemented in: comprehensive documentation for the study protocol, record keeping, training of field workers, and facilities, including computers and software. Phone inquiries were made to the managers of the selected practices to ask for their permission to conduct the study in their practice. After receiving written consent from them, one physician from each of these practices was asked for their willingness to participate in this study. On a set date, the fieldworker visited the participating PHC practice, obtained written consent from the PHC physician and handed her/him the questionnaire. Then, in the waiting-hall, the fieldworker consecutively invited the first 10 eligible patients who were visiting the selected PHC for various reasons to participate in the study. Women aged 18-55 years, with the ability to give informed consent were eligible to take part in the study.

In order to link individual participants with their responses we assigned each participant a study ID prior to collecting data. Each participant's name along with their unique study ID (eg, 001) were entered into a separate document. While collecting the data we entered each participant's unique study ID into their data document. To protect confidentiality, we used study codes on completed questionnaires and kept a separate document that linked the study code to subjects' identifying information locked in a separate location with restricted access to this document.

For the purpose of the study, two questionnaires were designed by the study team: one for patients and one for PHC physicians. The initial questionnaires were prepared based on information acquired from the review of international literature. We did not find similar studies so all the questionnaires' elements were designed by the authors after taking into consideration the aims of the research project. Both initially prepared questionnaires were then validated in a pilot study. There were 127 patients and 33 doctors in the pilot study who evaluated the face validity. The comments of the participants in the pilot study were directed at providing clarification of questions or adding more open questions. On the basis of both doctors and patients comments the final version of the questionnaire was developed. We used Cronbach's alpha to see if the multiple-item Likert scale questions were reliable. For 
each set of Likert scale questions, we achieved acceptable reliability (Cronbach's alpha $>0.6$ ).

After data analysis the posters explaining the results and conclusions were displayed in all practices where the study was conducted.

\section{Research tool}

Finally, the patient questionnaire consisted of 25 questions, including four multiple-item Likert scale and nine semi-open questions (see online supplementary file). The rest of the questions were multiple choice questions with the possibility to choose one or more predefined answers. The first set of questions was related to sociodemographic measures and the respondents' profile (number of pregnancies and children, gender of their FP, sexual activity). This part also involved questions regarding the patient's family medical history, specifically concerning female reproductive organ cancers. The next section integrated questions concerning the individuals' knowledge about cervical cancer and their attitude towards pap smears (how often do they undergo this examination, where, reasons for not doing this regularly). The last part of the questionnaire included a patient behavioural assessment which included questions regarding whether or not the patients wish to have the possibility of undergoing cervical cancer screening in their PHC office and why or why not.

The physicians' questionnaire data were gathered concerning the physicians' sex, age, location of the practice, number of patients seen at the practice per week, medical specialty and number of years in practice.

\section{Statistical analysis}

Statistical analysis was conducted using Statistica V.13.1 software. To present the results we used descriptive statistics. To investigate the associations between the attitude towards pap smears in a PHC setting and patients' and their doctors' characteristics, the $\chi^{2}$ test was used for qualitative variables and the Mann-Whitney $\mathrm{U}$ test was used for quantitative variables. Multivariate logistic regression analysis was used to measure for final associations between patients' characteristics and the willingness for screening in PHC adjusted for covariates.

There were few missing data in the questionnaires in different variables, although none of this was exceeding the $10 \%$ of all responses and therefore this was omitted in the final analysis. An alpha level of $\mathrm{p}=0.05$ was considered as statistically significant.

\section{RESULTS}

\section{Respondents' characteristics}

We reached 200 physicians in their PHC centres. Finally, 43 physicians agreed to participate in the study (response rate $21.5 \%$ ). Of all doctors participating-24 were women $(56 \%)$. The mean age of physicians was 39.5 years $( \pm \mathrm{SD}$ 9.25). The physicians' characteristics together with the dimension of their patients' features, depending on their willingness to undergo a pap smear in their practice are shown in table 1 .

Of 430 eligible patients, 418 consented to participate (response rate $97.2 \%$ ). The mean age of the patients was 39.1 years $( \pm$ SD 10.68). The patient's age did not have an influence on attitude towards cervical screening. Table 2 presents patients' characteristics.

\section{Patients' pap smear experience and values}

The majority of patients surveyed $(94 \%)$ indicated that they have had at least one pap smear performed at some time in the past. Less than a half $(46 \%)$ declared their last

Table 1 PHC physicians' characteristics and their patients' willingness to undergo pap smear screening at their PHC office

\begin{tabular}{|c|c|c|c|}
\hline PHC physicians' characteristics & $\begin{array}{l}\text { Patients willing to undergo } \\
\text { screening at his/her PHC } \\
\text { office } \mathrm{N}(\%)\end{array}$ & $\begin{array}{l}\text { Patients not willing to } \\
\text { undergo screening at his/ } \\
\text { her PHC office } \mathrm{N}(\%)\end{array}$ & $P$ value \\
\hline \multicolumn{4}{|l|}{ Gender } \\
\hline Female & $162(64.80)$ & $66(51.16)$ & \multirow[t]{2}{*}{$p=0.010$} \\
\hline Male & $88(35.20)$ & $63(48.84)$ & \\
\hline No & $11(4.53)$ & $14(11.93)$ & $p=0.009$ \\
\hline \multicolumn{4}{|l|}{ Population of patients } \\
\hline Adults and children & $173(71.19)$ & 87 (74.36) & \multirow[t]{2}{*}{$p=0.530$} \\
\hline Adults & $70(28.81)$ & $30(25.64)$ & \\
\hline More than 15 & $81(33.33)$ & 37 (31.62) & $p=0.362$ \\
\hline
\end{tabular}

PHC, primary healthcare. 
Table 2 Patients' characteristics and their willingness to undergo pap smear screening at their PHC office

\begin{tabular}{|c|c|c|c|}
\hline $\begin{array}{l}\text { Patients' } \\
\text { characteristics }\end{array}$ & $\begin{array}{l}\text { Willing to } \\
\text { undergo } \\
\text { screening at } \\
\text { PHC office } \\
\mathrm{N}(\%)\end{array}$ & $\begin{array}{l}\text { Not willing } \\
\text { to undergo } \\
\text { screening at } \\
\text { PHC office } \\
\text { N }(\%)\end{array}$ & $P$ value \\
\hline \multicolumn{4}{|l|}{ Place of living } \\
\hline Village & $69(28.05)$ & $62(48.06)$ & \multirow[t]{4}{*}{$p<0.001$} \\
\hline Town $<25000$ & $11(4.47)$ & $6(4.65)$ & \\
\hline $\begin{array}{l}\text { Town } 25000- \\
100000\end{array}$ & $28(11.38)$ & $18(13.95)$ & \\
\hline City $>100000$ & 138 (56.10) & 43 (33.33) & \\
\hline \multicolumn{4}{|l|}{ Education } \\
\hline $\begin{array}{l}\text { Less than high } \\
\text { school }\end{array}$ & 7 (27.78) & $6(4.51)$ & \multirow[t]{3}{*}{$p=0.256$} \\
\hline $\begin{array}{l}\text { High school } \\
\text { equivalent }\end{array}$ & $103(40.87)$ & $63(47.37)$ & \\
\hline $\begin{array}{l}\text { University } \\
\text { education }\end{array}$ & $142(56.35)$ & $64(48.12)$ & \\
\hline \multicolumn{4}{|l|}{ Marital status } \\
\hline Single & 72 (30.13) & $21(16.67)$ & \multirow[t]{4}{*}{$p=0.030$} \\
\hline Married & 151 (63.18) & $91(72.22)$ & \\
\hline Divorced & $13(5.44)$ & $12(9.52)$ & \\
\hline Widowed & $3(1.26)$ & $2(1.59)$ & \\
\hline \multicolumn{4}{|l|}{ Sexual activity } \\
\hline Yes & 206 (80.78) & 105 (79.55) & \multirow[t]{2}{*}{$p=0.771$} \\
\hline No & 49 (19.22) & $27(20.45)$ & \\
\hline
\end{tabular}

Family history

of female

reproductive

cancer

$\begin{array}{lrrr}\text { Yes } & 65(26.10) & 27(20.76) & \mathrm{p}=0.250 \\ \text { No } & 184(73.90) & 103(79.24) & \end{array}$

\begin{tabular}{lccc}
$\begin{array}{l}\text { Type of } \\
\text { gynaecological } \\
\text { visits }\end{array}$ & & & \\
\hline $\begin{array}{l}\text { Private practice } \\
\text { Private and }\end{array}$ & $114(44.88)$ & $55(41.35)$ & $\mathrm{p}=0.846$ \\
public practice & $11.33)$ & $8(6.02)$ & \\
$\begin{array}{l}\text { Public practice } \\
\text { None }\end{array}$ & $99(38.98)$ & $54(40.60)$ & \\
$\begin{array}{l}\text { Vaccination against } \\
\text { HPV }\end{array}$ & $16(6.30)$ & $30(22.56)$ & \\
$\begin{array}{l}\text { Yes } \\
\text { No }\end{array}$ & $12(4.78)$ & $7(5.38)$ & $\mathrm{p}=0.797$ \\
$\begin{array}{l}\text { Pap smear ever } \\
\text { done }\end{array}$ & $239(95.22)$ & $123(94.62)$ & \\
\hline $\begin{array}{l}\text { Yes } \\
\text { No }\end{array}$ & $20(7.84)$ & $5(3.82)$ & \\
\hline
\end{tabular}

HPV, human papillomavirus; PHC, primary healthcare.

\section{Reasons for}

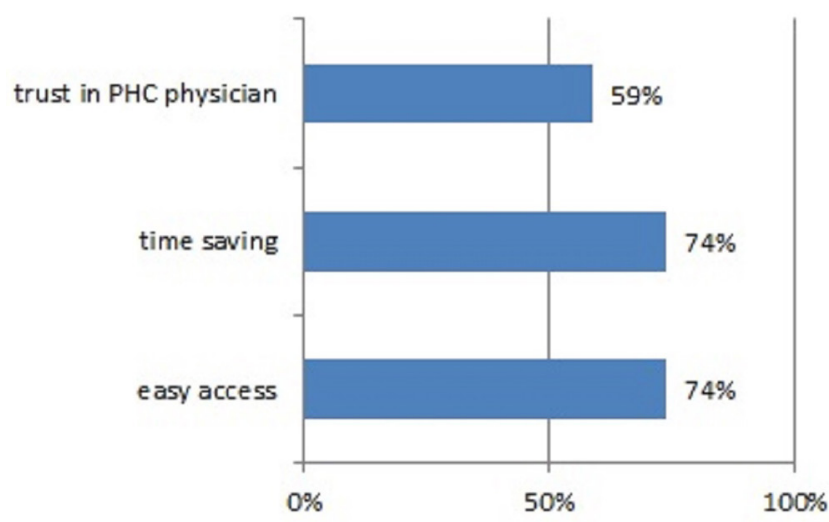

Figure 1 Patients'reasons for undergoing free pap smear by their PHC physician. PHC, primary healthcare.

pap smear was within the last 12 months, $34 \%$ indicated their last pap smear was 1-3 years ago and for $20 \%$ it was over 3 years ago. About $49 \%$ of study participants reported getting a pap smear regularly every 3 years, $32 \%$ of getting it once per year, $9 \%$ every 5 years and $10 \%$ less than every 5 years. Half of the studied patients paid privately for a pap smear. Only $8 \%$ of females received and responded to the National Health Service Fund's invitation to get pap smear testing financed by the government. Only $5 \%$ of respondents were vaccinated against HPV.

The most frequent reason (48\%) for not getting pap smears given by patients was not having any worrying symptoms, and therefore, they did not feel the need to get a pap smear. The other answers justifying non-adherence were as follows: lack of time $(39 \%)$, young age $(32 \%)$, embarrassment $(16 \%)$, fear of bad results $(12 \%)$.

Two-thirds of study participants declared a willingness to undergo free pap smear screening by their PHC physicians. In this group, most patients $(64 \%)$ agreed that by visiting a PHC office frequently, there will be no need to sacrifice additional time for pap smears at a specialist's office.

Figure 1 presents patients' motivations behind wanting to have their pap smear testing performed in their PHC office.

Among those objecting to receiving pap smears from PHC physicians (34\%), specialist care provided by gynaecologists in case of adverse results was the main concern (83\% of unwilling patients).

Figure 2 presents patients' reasons against undergoing free pap smear by their PHC physician.

\section{Factors affecting willingness to undergo pap smear in a PHC office}

Detailed information about the associations between patients' characteristics and the willingness to undergo screening at a PHC office is shown in table 2. Patients' features related with significantly higher will to undergo pap smear testing in a PHC setting were living in big cities 


\section{Reasons against}

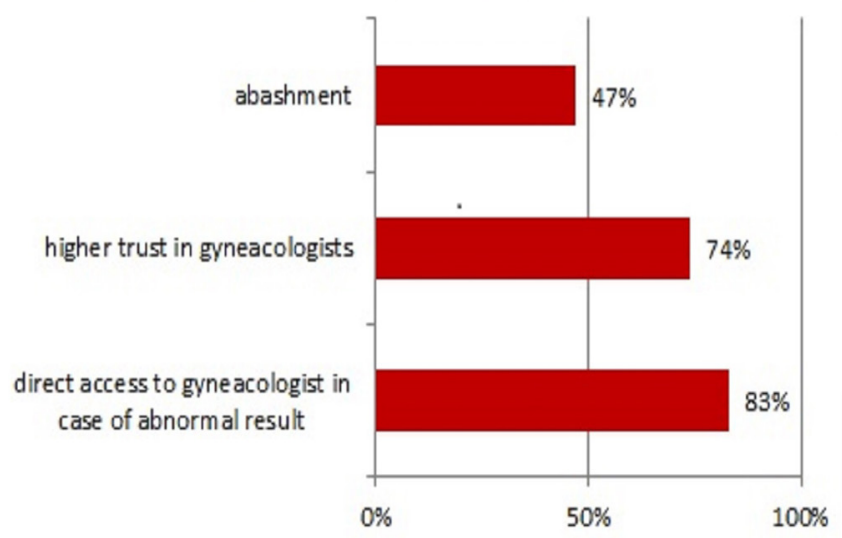

Figure 2 Patients'reasons against undergoing free pap smear by their primary healthcare physician.

and being single. Further analysis of the data hasn't shown a correlation between patients' age and the willingness to undergo pap smear in a PHC office $(\mathrm{p}=0.129)$. The results of the multivariate analysis are shown in table 3. Patients living in cities with population greater than 100000 citizens were more willing to undergo pap smear in PHC than village inhabitants $(\mathrm{OR}=2.76 ; \mathrm{p}<0.001)$. Regarding marital status, both married and divorced patients were less likely to agree for testing by PHC physicians than single patients $(\mathrm{OR}=0.51 ; \mathrm{p}=0.035$ and $\mathrm{OR}=0.33 ; \mathrm{p}=0.034$, respectively).

Table 1 presents associations between PHC physicians' characteristics and their patients' willingness to undergo pap smear screening at their PHC office. Our study revealed that the gender and specialty training in family medicine of the PHC doctor are also factors that have a positive influence on the patients' attitude in this matter. In fact, patients of female doctors were significantly more willing to have pap smears in their PHC office than patients whose doctor was male $(\mathrm{p}=0.010)$.

Physicians' age and workload featured by number of patient visits per week were not determining factors.

\section{DISCUSSION}

\section{Summary and interpretation of results}

Our findings provide a clearer picture of what factors influence cervical cancer screening rates. The study revealed that a majority of surveyed patients were willing to undergo pap smear screening at their PHC office. The reasoning behind this was that they do not need to seek a gynaecologist, will have shorter waiting times, their FP is more easily accessible and saving time for screening.

However, those who were unwilling were mostly concerned with possible lack of access to direct gynaecological consultation in case of abnormal or uncertain results.

This intersection of both patient and physician characteristics gives some insight into how the patient-doctor
Table 3 Logistic regression model: willingness to undergo screening in primary healthcare as associated with patients' characteristics (OR estimates and 95\% Cls of or estimates, reference group indicated in italics)

\begin{tabular}{|c|c|c|c|c|}
\hline \multicolumn{2}{|c|}{ Patients' characteristics } & \multirow[b]{2}{*}{ OR } & \multirow{2}{*}{$\begin{array}{l}\text { Lower } \\
\mathrm{Cl}\end{array}$} & \multirow{2}{*}{$\begin{array}{l}\text { Upper } \\
\mathrm{Cl}\end{array}$} \\
\hline Variable & Comparison & & & \\
\hline \multicolumn{5}{|c|}{ Place of living } \\
\hline \multirow[t]{3}{*}{ Village } & Town $<25000$ & 1.32 & 0.44 & 3.95 \\
\hline & Town 25000-100000 & 1.46 & 0.70 & 3.07 \\
\hline & City $>100000$ & 2.76 & 1.59 & 4.79 \\
\hline \multicolumn{5}{|l|}{ Education } \\
\hline \multirow{2}{*}{$\begin{array}{l}\text { Less than } \\
\text { high school }\end{array}$} & High school equivalent & 0.55 & 0.15 & 2.04 \\
\hline & University education & 0.59 & 0.16 & 2.26 \\
\hline
\end{tabular}

\begin{tabular}{|c|c|c|c|c|}
\hline \multicolumn{5}{|c|}{ Marital status } \\
\hline \multirow[t]{3}{*}{ Single } & Married & 0.51 & 0.27 & 0.95 \\
\hline & Divorced & 0.33 & 0.12 & 0.93 \\
\hline & Widowed & 0.76 & 0.10 & 5.64 \\
\hline \multicolumn{5}{|c|}{ Sexual activity } \\
\hline No & Yes & 0.59 & 0.30 & 1.18 \\
\hline \multicolumn{5}{|c|}{ Family history of female reproductive cancer } \\
\hline No & Yes & 0.75 & 0.43 & 1.30 \\
\hline \multicolumn{5}{|c|}{ Type of gynaecological visits } \\
\hline \multirow[t]{3}{*}{ None } & Private practice & 0.91 & 0.41 & 2.02 \\
\hline & $\begin{array}{l}\text { Private and public } \\
\text { practice }\end{array}$ & 0.76 & 0.35 & 1.66 \\
\hline & Public practice & 0.60 & 0.18 & 2.01 \\
\hline \multicolumn{5}{|c|}{ Vaccination against HPV } \\
\hline No & Yes & 1.68 & 0.57 & 4.92 \\
\hline \multicolumn{5}{|c|}{$\begin{array}{l}\text { Pap smear } \\
\text { ever done }\end{array}$} \\
\hline No & Yes & 1.49 & 0.47 & 4.53 \\
\hline \multicolumn{5}{|l|}{ Age } \\
\hline & & 0.86 & 0.25 & 3.01 \\
\hline
\end{tabular}

HPV, human papillomavirus.

relationship is crucial in maintaining adherence to screening regimes. We found that female FP were more likely to have patients well-disposed to undergoing pap smears in the PHC setting. A likely reason for this is a greater level of comfort for the patient to have gynaecological procedures performed by a physician of the same sex.

The only physician characteristic to significantly impact patient openness to screening in the PHC setting was a specialisation in family medicine (according to the current law in Poland, the PHC doctors can be specialists in family medicine, paediatrics or internal medicine).

This could be accounted for by the unique characteristics that set FPs apart from other specialties-longer, deeper patient relationships, a greater focus on patient 
education, greater comfort with screening and perhaps the greater emphasis placed on women's health in family medicine practice than in internal medicine or another specialisation. It is important to note that neither the age of the doctor nor the size of the patient load were correlated with patient disposition toward screening; and similarly, among patients neither age nor education were found to be significant.

Of the patient characteristics studied, it was found that marital status (being single) and area of residence (living in a city) where significantly correlated with willingness to undergo pap smears in the PHC setting. Considering that age is not a confounding factor, the significance of marital status could be explained as an increased awareness in single women of sexually transmitted diseases and so a tendency to view screening as important and routine; if single women are more likely to see the utility of a pap smear, they would also be more likely to have it done in a PHC setting where it is more easily accessible.

The fact that living in a city is significant on the other hand, speaks quite clearly to cultural differences between urban and rural centres in the attitude toward screening, personal modesty, what the traditional roles of doctors should be and different levels of exposure to medical practice.

\section{Strengths and limitations of the study}

Gathered data allowed for an examination of the individual factors which may influence patients' behaviours when they are considering undergoing cytological testing at their PHC office. The strength of the study was also the possibility of joining the patients' answers with the characteristics of their physicians.

Additionally, the study was conducted in randomly selected PHC offices, with the minimal sample size reached in both: physician and patient groups, and included participants from urban, suburban and rural communities. The study was performed anonymously so we may suspect that respondents answered the questions truthfully.

Nevertheless, the study also had some limitations. The results are not fully representative of the whole Polish population due to the survey only being conducted in one, however, large region. So, there is no reason to believe that in other regions the situation might be better. Moreover, only patients who visited their PHC physician were questioned. We may suspect that there is a number of patients who are not visiting their PHC office and that some of them receive pap smears at their gynaecologists' offices while the rest are not regularly seeking medical care at all.

Even though the estimation of the percentage of women who regularly perform the pap smears was not the primary focus of our study, we noted that received results showed a higher percentage of women who declare receiving regular pap smears compared with national statistics. This may be due to the fact that not all pap smears done by private gynaecologists are recorded in the general Polish data base, and that we need to approach the national data with caution.

On the other hand, it is also possible that the study participants provided responses which are more socially desirable, even when answering anonymously, thereby inflating the number of women receiving screening. This might be due to the fact that numerous public campaigns are trying to encourage women to perform regular pap smears. Moreover, we received answers from women who might be more concerned about their health as they visit their FPs, in comparison to other potential patients who don't.

Nonetheless, the percentage of women who would be willing to receive pap smears at their general practitioner (GP) office is high, which is valuable information from a cost-allocation perspective. Also, the studied group are patients whose attitudes towards pap smears may be potentially influenced by their physicians, therefore the population is congruent with the purpose of the study.

\section{Comparison with other studies}

Our findings were in line with a study performed by Favre et al in 2018 in France, a nation where similarly GPs often do not perform pap smears. ${ }^{19}$ In their study, the participation rate in cervical cancer screening was slightly higher when a PHC physician performed smears and when the physician was female. The study assessing patient and physician factors influencing participation in cervical cancer screening in Norway revealed that higher non-adherence rates were associated with having a male PHC physician, which is in line with our findings. ${ }^{20}$ An interesting finding of a recent study in Serbia was that women who regularly received pap smears showed more neutral when choosing a gynaecologist, unlike the less adherent groups that preferred a female physician. ${ }^{21}$ This suggests that with cervical cancer screening becoming more widespread, the barrier to have the test performed by a male PHC physician may lessen. This study also revealed that women irregularly or never received a pap smear mainly because of lack of knowledge about pap smears, difficult access to healthcare facilities, lack of time, discomfort and anxiety of pap smear results. ${ }^{21}$ A study performed in Switzerland revealed that the main reasons for non-participation in cervical cancer screening were practical barriers, such as lack of time and the cost of screening. ${ }^{22}$ The two aforementioned studies and our study support the idea that convenience and accessibility may be major obstacles in achieving a greater degree of cervical cancer screening in the population. In the Norwegian study, higher non-adherence rates were associated with a greater distance to the screening site which is indirectly consistent with our results with regard to living in an urban setting. ${ }^{20}$ We found being single was associated with a higher likelihood to agree to pap smear screening in the PHC office, though Leinonen $e t a l$ and a study in Lithuania by Petkeviciene et al, found being single was 
associated with non-adherence, suggesting that willingness to undergo screening and later adherence are not necessarily correlated..$^{23}$

\section{Implications for practice and screening policy}

There is a need to educate women regarding the importance of cervical cancer screening. The role of FPs as health advocates, as well as a community resource for health education, is essential to reduce the morbidity and mortality from cervical cancer. Our results demonstrate that too many women were neglecting their screening because they had no symptoms. Clearly it is vital that doctors inform patients of the silent nature of cervical cancer, and that the purpose of the screening test is not to confirm a diagnosis, but rather precisely to catch the cancer when it is still asymptomatic. Statements such as these show that patients do not understand the fundamental purpose of the screening test; adherence will not increase if patients are not clear as to the aim of the test. In addition, fears concerning the safety of the test and the need for 'specialised' interventions should adverse events occur also reveal a need for a greater level of patient education. Formal intensive screening for cervical cancer should be launched and supported across Poland. These services if conducted at PHC offices could potentially avoid long wait times and additional scheduling complexity at gynaecological offices.

In order to decrease the mortality of patients with positive cytological testing, there should be a fast track system to gynaecological care in place to expedite medical or surgical treatment. We believe that results from this investigation will streamline the organisation of a pilot study with the goal of studying and introducing more effective cervical cancer screening in the Małopolska region and therefore promote improvements to current Polish PHC.

\section{CONCLUSION}

It is crucial to improve the accessibility to cervical cancer screening for patients in Poland. Strategies must be tailored to the needs of the patients; effective approaches should be multifaceted. This requires effective interventions that will concentrate not only on increasing awareness of the importance of prevention and the need for regular pap smears, but also by providing convenient means by which to undergo the test. Taking into the account the high mortality of the cervical cancer in Poland we believe that our study shows possible area of improvement.

Acknowledgements The authors wish to thank Sze Kay Frances Chan and Natalia Augustyn for their assistance in data gathering. In addition to that, the authors would like to thank all patients and doctors who took part in the pilot study and helped creating the finale version of the study tool.

Contributors All authors mentioned contributed to the study. All authors read and approved the final manuscript. MS, MC, FB: gathering the data; AK-K: data analysis. $\mathrm{KN}$ reviewed the literature, analysed and interpreted the data and drafted the manuscript. AW and SKFC analysed and interpreted the data and revised the manuscript for important intellectual content. MC, SKFC, FB reviewed the literature and revised the manuscript for important intellectual content. KN and AK-K designed the questionnaire, designed the study and revised the manuscript for important intellectual content. EK-R conceived and designed the study and drafted the manuscript. All authors helped with the revision of the manuscript.

Funding The authors have not declared a specific grant for this research from any funding agency in the public, commercial or not-for-profit sectors.

Competing interests None declared.

Patient consent for publication Informed consent was obtained from all patients and physicians.

Ethics approval The study was approved by the Jagiellonian University Bioethics Committee, nr KBET/122.6120.15.2017.

Provenance and peer review Not commissioned; externally peer reviewed.

Data availability statement Data are available upon reasonable request.

Open access This is an open access article distributed in accordance with the Creative Commons Attribution Non Commercial (CC BY-NC 4.0) license, which permits others to distribute, remix, adapt, build upon this work non-commercially, and license their derivative works on different terms, provided the original work is properly cited, appropriate credit is given, any changes made indicated, and the use is non-commercial. See: http://creativecommons.org/licenses/by-nc/4.0/.

\section{REFERENCES}

1. Castellsagué X. Natural history and epidemiology of HPV infection and cervical cancer. Gynecol Oncol 2008;110(3 Suppl 2):S4-S7.

2. Bosch FX, Lorincz A, Muñoz N, et al. The causal relation between human papillomavirus and cervical cancer. J Clin Pathol 2002;55:244-65.

3. Faridi R, Zahra A, Khan K, et al. Oncogenic potential of human papillomavirus (HPV) and its relation with cervical cancer. Virol $J$ 2011;8:269.

4. Clifford GM, Smith JS, Aguado T, et al. Comparison of HPV type distribution in high-grade cervical lesions and cervical cancer: a meta-analysis. Br J Cancer 2003;89:101-5.

5. Roden R, Wu T-C. How will HPV vaccines affect cervical cancer? Nat Rev Cancer 2006;6:753-63.

6. zur Hausen H. Papillomaviruses and cancer: from basic studies to clinical application. Nat Rev Cancer 2002;2:342-50.

7. Muñoz N, Bosch FX, de Sanjosé S, et al. Epidemiologic classification of human papillomavirus types associated with cervical cancer. $N$ Engl J Med 2003;348:518-27.

8. Markowitz LE, Hariri S, Lin C, et al. Reduction in human papillomavirus (HPV) prevalence among young women following HPV vaccine introduction in the United States, National health and nutrition examination surveys, 2003-2010. J Infect Dis 2013;208:385-93.

9. Koutsky LA, Ault KA, Wheeler CM, et al. A controlled trial of a human papillomavirus type 16 vaccine. N Engl J Med 2002;347:1645-51.

10. Nygård JF, Skare GB, Thoresen $S \varnothing$. The cervical cancer screening programme in Norway, 1992-2000: changes in Pap smear coverage and incidence of cervical cancer. J Med Screen 2002;9:86-91.

11. McGraw SL, Ferrante JM. Update on prevention and screening of cervical cancer. World J Clin Oncol 2014;5:744-52.

12. Fisher JW, Brundage SI. The challenge of eliminating cervical cancer in the United States: a story of politics, prudishness, and prevention. Women Health 2009;49:246-61.

13. Cuzick J, Clavel C, Petry K-U, et al. Overview of the European and North American studies on HPV testing in primary cervical cancer screening. Int J Cancer 2006;119:1095-101.

14. Peto J, Gilham C, Fletcher O, et al. The cervical cancer epidemic that screening has prevented in the UK. The Lancet 2004;364:249-56.

15. Andrae B, Andersson TML, Lambert PC, et al. Screening and cervical cancer cure: population based cohort study. BMJ 2012;344:e900.

16. Bruni L, Barrionuevo-Rosas L, Albero G, et al. ICO information centre on HPV and cancer (HPV information centre). human papillomavirus and related diseases in Poland. Summary Report 2016.

17. Yabroff KR, Saraiya M, Meissner HI, et al. Specialty differences in primary care physician reports of Papanicolaou test screening practices: a national survey, 2006 to 2007. Ann Intern Med 2009;151:602-11.

18. Pollak KI, Krause $\mathrm{KM}$, Yarnall $\mathrm{KSH}$, et al. Estimated time spent on preventive services by primary care physicians. BMC Health Serv Res 2008;8:245.

19. Favre J, Rochoy M, Raginel T, et al. The effect of cervical smears performed by general practitioners on the cervical cancer screening 
rate of their female patients: a claim database analysis and crosssectional survey. Journal of Women's Health 2018;27:933-8.

20. Leinonen MK, Campbell S, Klungsøyr O, et al. Personal and provider level factors influence participation to cervical cancer screening: a retrospective register-based study of 1.3 million women in Norway. Prev Med 2017;94:31-9.

21. Jovanovic V, Mitrovic Jovanovic A, Zivanovic A, et al. Knowledge about cervical cancer, Pap test, and barriers to women's participation in screening in Belgrade, Serbia. Eur J Gynaecol Oncol 2017;38:69-75.

22. Catarino RR, Vassilakos PP, Royannez-Drevard II, et al. Barriers to cervical cancer screening in Geneva (DEPIST study). J Low Genit Tract Dis 2016;20:135-8.

23. Petkeviciene J, Ivanauskiene R, Klumbiene J. Sociodemographic and lifestyle determinants of non-attendance for cervical cancer screening in Lithuania, 2006-2014. Public Health 2018;156:79-86. 